\title{
Investigation of the steel parts' hardsurfacing overlays properties
}

\author{
Vladimir Malikov ${ }^{1 *}$ and Alexey Ishkov $^{2}$ \\ ${ }^{1}$ Altay State University, 656049, Barnaul, Russia \\ ${ }^{2}$ Altay State Agricultural University, 656049, Barnaul, Russia
}

\begin{abstract}
The article describes the studies' results of steels with applied boron-based hardsurfacing overlays. The overlay was done in four different ways. The materials obtained differed in chemical composition, properties and wear resistance. A detailed technical process of surfacing and the surfacing charge composition, which makes it possible to obtain the necessary material, is given. Studies of hardness, macro- and microstructure, chemical and X-ray phase composition of the obtained materials have been carried out. The descriptions of the overlays' characteristic phases are made and their properties are given. The chemical composition of the obtained overlays has been determined by the emission spectroscopy method. The $\mathrm{X}$-ray phase analysis of the samples has also been carried out and the percentage of the additional modifier introduced into the overlays has been determined. Based on the results of the studies carried out, the conclusions about the optimal method of metal hardening have been drawn.
\end{abstract}

\section{Introduction}

As it is known, in the last 3-5 years, instead of the widely used $65 \mathrm{G}$ steel, manufacturers have been increasingly using boron steel for the manufacture of working parts for the machines $30 \mathrm{MnB} 5$ (mainly for the working bodies of machines), and tungsten-containing steel is recommended to replace the same steel in cutting elements (cutters) 5-6KHV2C.

However, despite certain advantages in wear resistance, these materials are characterized by a 1.5-2 times higher cost, have higher heating temperatures for hardening $800-900{ }^{\circ} \mathrm{C}$, as well as increased requirements for heat treatment (narrow temperature and increased time intervals of austenite conditioning, tempering, require increased isothermal quenching, etc.), which also increases the cost of parts. For example, steel $6 \mathrm{KHV} 2 \mathrm{C}$ when quenching to maximum hardness, is very sensitive to the temperature of quenching and tempering, as well as the time of these processes (up to 2-3 hours), and after heat treatment, a soft decarburized layer up to $1 \mathrm{~mm}$ forms on its surface, which requires final machining of the part or the use of protective media in ovens.

At the same time, during cutting in the high temperature zone (up to $620-630^{\circ} \mathrm{C}$ ) oxides form on the working surfaces of these materials, which significantly reduce the wear

\footnotetext{
*Corresponding author: osys11@gmail.com
} 
resistance of HSS cutting tools. To increase the wear resistance of the tool, various hardening methods are used, including the application of protective overlays [1].

To harden the cutting edge of the investigated parts in modern technologies, the methods of applying various hard, wear-resistant and functional overlays are widely used: gas-flame, arc, laser and plasma surfacing, induction (HFC) surfacing, creation of bimetallic elements on the cutting edge by cladding, etc. As materials for such overlays, wear-resistant alloy cast irons, ductile nickel steels, composite materials on an iron and / or nickel base, ceramics are used.

The wear resistance of these surfacing materials strongly depends on their structure, the type and amount of hardening phases in the alloys. Surfacing processes, due to differences in the values of heat input and properties of electrode materials, have a specific effect on the overlays' properties [2-11]. For example, in [2], the effect of copper on metal was investigated. The alloys were remelted 4 times to improve the homogeneity of the material. The deterioration of the metal plasticity with an insignificant increase in hardness has been established. In $[4,5]$, the studies of alloys containing more than 5 elements in almost equal ratios were carried out and it was shown that the structure of such an alloy directly affected its mechanical properties. In [6], a series of alloys $\mathrm{Cu}-\mathrm{Ni}-\mathrm{Al}-\mathrm{Co}-\mathrm{Cr}-\mathrm{Fe}-\mathrm{Si}$, having different ratios of the main elements, was analyzed, while 5 cycles of surfacing were performed.

In [7], the microstructure of the alloy $\mathrm{Zr}-2.5 \mathrm{Nb}$, resulting from surfacing with different heat input rates was analyzed. The influence of the obtained alloy structure on the mechanical properties of the substance was investigated.

In [8], the degree of grain overlap coefficient influence in the fusion region was estimated. It was found that as the overlap coefficient increases, the width of the region consisting of martensite increases, which leads to a decrease in the microhardness gradient from the melting zone to the base metal. In $[9,11]$, to study the surface topography of the Zircaloy alloy-4 $\left(\mathrm{LBWZr}_{4}\right)$ using scanning electron microscopy.

In [10], the fatigue wear of a sample subjected to laser surfacing was determined. According to the test results, damage probabilities to the hardened specimen at various loads were determined.

$[12,13]$ show the effect of corrosion on the hardened alloy properties. The alloy was hardened by a laser, while the oxygen content in the surfacing chamber was changed. A significant influence of the oxygen content on the corrosion resistance of the hardened alloy has been established.

In this paper, we study hardsurfacing overlays that differ in composition, properties and wear resistance, consider various surfacing processes and charge compositions that are optimal for the use in industry and the agricultural sector.

\section{Materials and methods}

During the study, four methods of hardening cutters were tested: induction surfacing of hard alloy with modifiers of hardness, friction and wear resistance for $2 / 3$ of the blade length (Rostov 1), surfacing an alloy with 2 modifiers (Rostov 2), surfacing on pre-modified electrospark ligation surface (Basic 1), and control surfacing with a standard charge without modifiers (Basic 2).

As the main modifier of wear resistance, both compositions contained spherical tungsten carbide powder, fraction $\varnothing 0,25-0,5 \mathrm{~mm}$, Boron carbide was used as an additional modifier, and the composition of Rostov 2 additionally contained nickel powder introduced instead of the hard alloy to maintain the optimal balance of the metal matrix and the ceramic filler. Instead of welding flux Akh-348 borate flux is used in the charge P-0,66 [14]. 
Surfacing was carried out as follows: all alloy components were loaded into the charge filling, and placed in an acidic (quartz) ceramic crucible, grade Fornax-T®, volume of 110 ml. In addition, a borating charge containing, wt. \%: 80-85 $\mathrm{B}_{4} \mathrm{C}$ or $\mathrm{WC}$ and $15-20$ wt. \% gumboil P-0,66, after which the contents of the crucible were mixed.

The crucible was placed in a vertical inductor made of a copper tube, with $\mathrm{D}=10 \mathrm{~mm}$, thermally insulated with asbestos, and connected to an industrial HFC- installation ELSIT-45-75/100, and melting was carried out with the following parameters: inductor current $\mathrm{I}=50-75 \%$, frequency $\mathrm{f}=45-50 \mathrm{kHz}$, time $\mathrm{t}=80-120 \mathrm{~s}$, with two stops at 60 and 80 $\mathrm{s}$, for guiding and removing (draining) slag through the side opening of the crucible. The melting was completed by the calming down of the boiling of the metal in the crucible, and the cessation of gas evolution (the disappearance of the greenish torch of copper and sparks).

The finished liquid alloy was quickly poured together with slag into a bucket of hot water $\left(85-95{ }^{\circ} \mathrm{C}\right)$, and, after cooling, they were removed from the bottom in the form of beads, drops and balls, after removing the slag from the water surface with a slotted spoon and decanting the water. Then the finished alloy was washed with water, then with alcohol and acetone, and dried in open air. The yield of the finished wear-resistant alloy (according to the material balance of the initial metal components of the melt) was $95-98 \%$.

A layer of charge, 2-3 mm thick, with a fineness of ingredients less than 315 microns, was placed on steel blanks with a size $20 \times 30 \times 5 \mathrm{~mm}$, and carried out HFC - heating and induction surfacing on the same high-frequency equipment with the following parameters: inductor current $\mathrm{I}=85-95 \%$, frequency $\mathrm{f}=70-75 \mathrm{kHz}$, time $\mathrm{t}=90-120 \mathrm{~s}$.

\section{Research results}

In the prepared samples, the following properties were investigated: hardness, macro- and microstructure, hardness and phase (morphological) composition of the overlay, chemical and $\mathrm{X}$-ray phase composition. The hardness of the obtained overlays is given in Table 1.

Table. 1. Hardness (average) of the obtained hardsurfacing overlays

\begin{tabular}{|l|l|l|}
\hline No. & Method of hardening, charge & $\mathrm{HRC}_{\mathrm{e}}$ \\
\hline 1 & 1, Rostov 1 & $60-65$ \\
\hline 2 & 2, Rostov 2 & $52-55$ \\
\hline 3 & 3, Basic 1 & $52-53$ \\
\hline 4 & 4, Basic 2 & $52-55$ \\
\hline
\end{tabular}

Macro photography research $(50 \times)$ thin sections of hardsurfacing overlays makes it possible to distinguish the main structures (characteristic phases) of the overlay components by the morphology of their most typical areas and to determine their characteristics. An example of the obtained macrophotography is shown in Fig. 1.

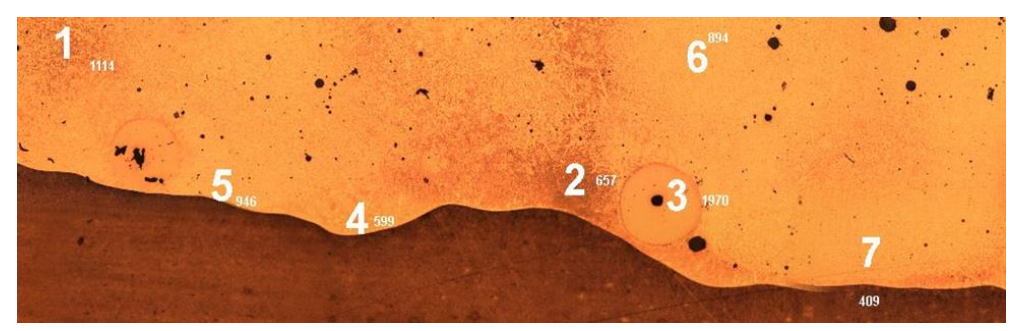

Fig. 1. Closeup $\left(50^{\times}\right)$hardsurfacing overlay, indicating typical areas (phases) and their microhardness 
Table 2 summarized information on the characteristic phases of hardsurfacing overlays obtained on steel $65 \mathrm{G}$, HFC- by surfacing in various ways and from various charge materials.

Table 2. Description of typical overlay phases and their properties

\begin{tabular}{|c|c|c|c|}
\hline $\begin{array}{l}\text { Method, } \\
\text { charge }\end{array}$ & $\begin{array}{l}\text { Overlay } \\
\text { phases }\end{array}$ & Structure type, morphology & $\begin{array}{c}\text { Microhardness, } \\
\text { HV }\end{array}$ \\
\hline \multirow[t]{6}{*}{ 1, Rostov 1} & 1 & $\begin{array}{l}\text { Finely dispersed boride eutectic, poorly } \\
\text { demarcated gray areas with impurities of } \\
\text { octahedral fused and ground carbides }\end{array}$ & $1080-1100$ \\
\hline & 2 & $\begin{array}{l}\text { Remelted ledeburite-like eutectic, dark } \\
\text { and gray with fine structure }\end{array}$ & $640-660$ \\
\hline & 3 & $\begin{array}{c}\text { Spherical tungsten carbide, structureless } \\
\text { spherical impurities with a clear } \\
\text { boundary }\end{array}$ & $1900-2000$ \\
\hline & 4 & $\begin{array}{l}\text { Dendritic structures, columnar, distinct } \\
\text { and branched light formations on the } \\
\text { border with the base metal }\end{array}$ & $500-700$ \\
\hline & 5 & $\begin{array}{l}\text { Boride eutectic, light areas on the border } \\
\text { with the base metal }\end{array}$ & $900-1000$ \\
\hline & 6 & $\begin{array}{c}\text { Carbide eutectic with carbide impurities, } \\
\text { weakly delimited light areas with } \\
\text { needle-like impurities }\end{array}$ & $800-900$ \\
\hline \multirow[t]{4}{*}{ 2, Rostov 2} & 1 & $\begin{array}{c}\text { Carbide eutectic with carbide impurities, } \\
\text { poorly demarcated gray areas with } \\
\text { needle-like impurities }\end{array}$ & $900-950$ \\
\hline & 2 & $\begin{array}{l}\text { Fused boride eutectic, light areas at the } \\
\text { interface with the base metal }\end{array}$ & $850-900$ \\
\hline & 3 & $\begin{array}{c}\text { Spherical tungsten carbide, structureless } \\
\text { spherical impurities with a clear } \\
\text { boundary, cracks }\end{array}$ & $1600-1700$ \\
\hline & 4 & $\begin{array}{l}\text { Boride eutectic, light areas at the border } \\
\text { with pores and boron carbide impurities }\end{array}$ & $1000-1100$ \\
\hline \multirow[t]{4}{*}{3 , Basic 1} & 1 & $\begin{array}{l}\text { Carbide eutectic, the main type of } \\
\text { structure in the deposited layer }\end{array}$ & $700-750$ \\
\hline & 2 & $\begin{array}{l}\text { Dendritic structures, columnar, distinct } \\
\text { and branched light formations on the } \\
\text { border with the base metal }\end{array}$ & $500-550$ \\
\hline & 3 & $\begin{array}{c}\text { Carbide eutectic with carbide impurities, } \\
\text { poorly demarcated gray areas with } \\
\text { octahedral and acicular impurities }\end{array}$ & $900-1000$ \\
\hline & 4 & $\begin{array}{l}\text { Carbides at the interface with the base } \\
\text { metal, acicular structures in the gray field } \\
\text { between dendrites }\end{array}$ & $700-750$ \\
\hline \multirow[t]{3}{*}{ 4, Basic 2} & 2 & $\begin{array}{c}\text { Finely dispersed carbide eutectic, lighter, } \\
\text { main overlay layer }\end{array}$ & $800-850$ \\
\hline & 3 & $\begin{array}{l}\text { Non-metallic impurities, particles of } \\
\text { irregular shape with clear boundaries }\end{array}$ & $550-600$ \\
\hline & 6 & $\begin{array}{c}\text { Eutectic with impurities of crushed } \\
\text { dendrites and acicular carbides, a darker }\end{array}$ & $900-950$ \\
\hline
\end{tabular}




\begin{tabular}{|l|l|c|l|}
\hline & & $\begin{array}{c}\text { interlayer at the interface with the base } \\
\text { metal }\end{array}$ & \\
\hline
\end{tabular}

The fine structure of the overlays and the effects caused by the modification of the charge materials with tungsten and boron carbides are clearly visible in micrographs of the hardsurfacing overlays. An example of the obtained micrograph is shown in Fig. 2.

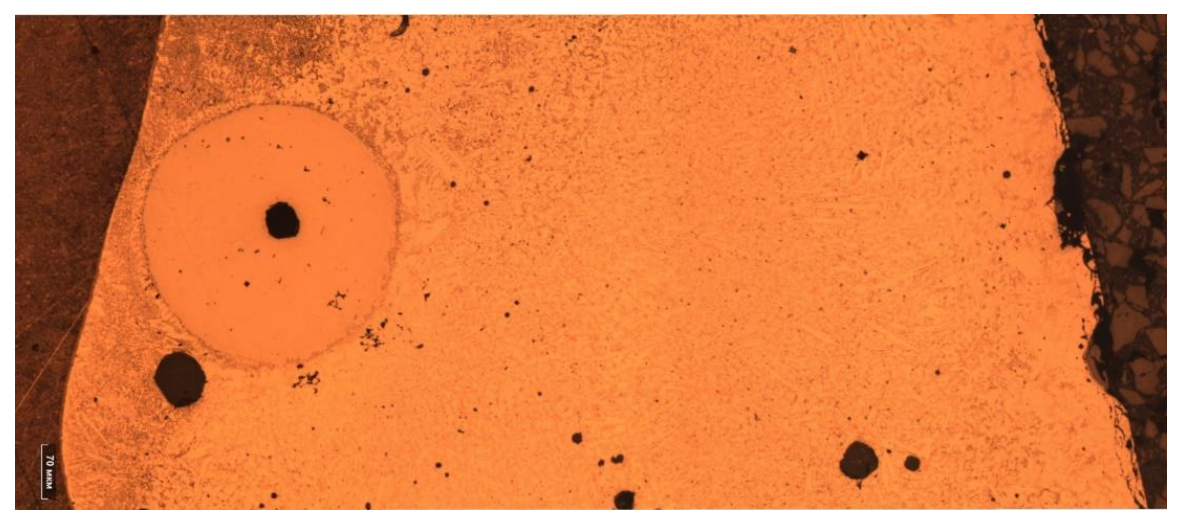

Fig. 2. Microstructure of the 1 st sample overlay with $\mathrm{WC}\left(100^{\times}\right)$particle

The chemical composition of the hardsurfacing overlays was determined by the method of emission spectroscopy, for which the upper part of the cutters' hardened blanks was used (Fig. $3)$.

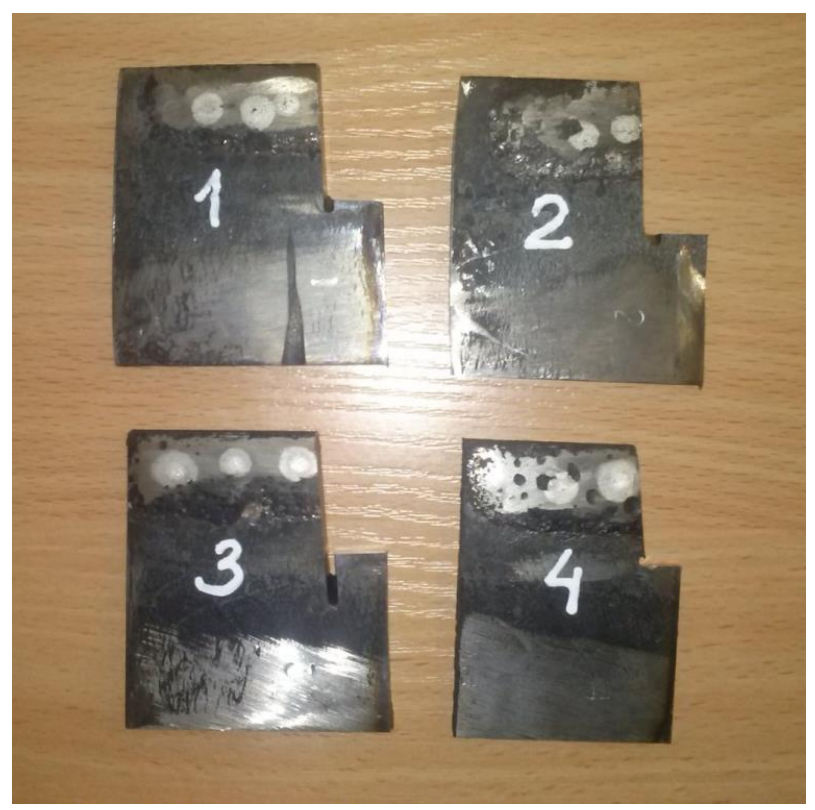

Fig. 3. Samples of the cutters' hardsurfacing overlays, prepared for emission spectral analysis

The results of the overlays chemical analysis obtained by various methods are shown in Table 3. 
Table 3. The chemical composition of the overlay material of the samples (excluding iron), wt. \%

\begin{tabular}{|l|l|l|l|l|l|l|l|l|l|}
\hline $\mathrm{C}$ & $\mathrm{Si}$ & $\mathrm{Cr}$ & $\mathrm{Mn}$ & $\mathrm{Ni}$ & $\mathrm{W}$ & $\mathrm{Mo}$ & $\mathrm{B}$ & $\mathrm{P}$ & $\mathrm{S}$ \\
\hline \multicolumn{8}{|c|}{ 1st sample } \\
\hline $2.9-$ & $1.2-$ & $22.6-$ & $0.9-$ & $1.05-$ & $2.2-$ & $0.12-$ & $2.3-$ & $0.02-$ & $0.13-$ \\
4.1 & 1.4 & 23.3 & 0.82 & 2.1 & 3.8 & 0.18 & 3.5 & 0.06 & 0.19 \\
\hline \multicolumn{8}{|c|}{ nd sample } \\
\hline $3.6-$ & $0.9-$ & $22.8-$ & $0.7-$ & $\begin{array}{l}2.8- \\
3.5\end{array}$ & $5.2-$ & $0.09-$ & $5.2-$ & $0.02-$ & $0.11-$ \\
4.2 & 1.0 & 26.1 & 1.1 & 3.5 & 6.0 & 0.19 & 6.9 & 0.04 & 0.20 \\
\hline \multicolumn{8}{|c|}{ 3rd sample } \\
\hline $3.81-$ & $0.6-$ & $25.9-$ & $0.7-$ & $1.9-$ & $0.23-$ & $0.13-$ & $0.8-$ & $0.01-$ & $0.04-$ \\
3.85 & 1.3 & 28.3 & 0.9 & 2.0 & 0.26 & 0.16 & 0.9 & 0.02 & 0.05 \\
\hline \multicolumn{8}{|c|}{ 4th sample } \\
\hline $3.8-$ & $0.6-$ & $24.3-$ & $0.8-$ & $1.9-$ & $0.6-$ & $0.17-$ & $0.7-$ & $0.02-$ & $0.04-$ \\
3.9 & 0.9 & 29.4 & 0.9 & 2.3 & 0.7 & 0.21 & 1.0 & 0.04 & 0.05 \\
\hline
\end{tabular}

The main component of all hardsurfacing overlays is iron, the amounts of carbon, main alloying elements $(\mathrm{Cr}, \mathrm{Mn})$ and silicon are approximately constant and coincide with the corresponding values for a pure (unmodified) material PG-S27.

The content of other elements included in the modifiers or additionally introduced into the charge or on the surface of the workpiece before surfacing (Ni, W, Mo, B) as a whole (semi-quantitatively) change symbatically with the amount of introduced components.

The increase in the phosphorus content and, especially, sulfur in the samples 1 and 2, which is obviously associated with their appearance from the commercial boron carbide used for the modification.

Fluctuations in the chemical composition of hardsurfacing overlays materials are caused by their macro-inhomogeneity, due to the use of multicomponent powder compositions for surfacing and a short time of the metallurgical process, as well as micro-inhomogeneity, due to their uneven distribution between the phases of overlays and segregation.

Since boron carbide introduced into the composition of overlay materials can chemically interact with iron, chromium and other elements that make up the composition of the hard alloy PG-S27, with the formation of new solid, wear-resistant phases: $\mathrm{Fe}_{2} \mathrm{~B}, \mathrm{FeB}, \mathrm{CrB}$ and others, an X-ray phase study of overlays was carried out by the method of X-ray phase analysis (X-ray) on the samples prepared from the upper part of the hardened blanks of cutters (Fig. 4). X-ray results are shown in Fig. 5-7 and in Table. 4.

The radiographs shown in Fig. 5-7, which turned out to be an uninformative area of diffraction angles $2 \square$ from 50 till 80 discarded. The study showed that samples 1 and 2 have a similar X-ray diffraction pattern of the overlay, sample 3 was studied as a control one, since it is known that such an overlay always contains chromium and iron carbides, in the sample 4 it was supposed to detect on the X-ray diffraction pattern introduced to the surface at electrospark ligation Wolfram carbide.

However, as shown by the results of decoding the X-ray diffraction patterns, the main phases detected in all overlays turned out to be: $\alpha$-Fe, $\mathrm{FeC}$ (austenite), iron carbides $\mathrm{Fe}_{3} \mathrm{C}$, $\mathrm{Fe}_{7} \mathrm{C}_{3}$, chromium carbides $\mathrm{CrC}, \mathrm{Cr}_{7} \mathrm{C}_{3}$. Preliminarily introduced $\mathrm{WC}$ tungsten carbide was also found in the overlays of the samples 1 and 2, which, however, is absent in the sample 4. Boron carbide, as well as iron and (or) chromium borides, were not found in the samples 1 and 2. 


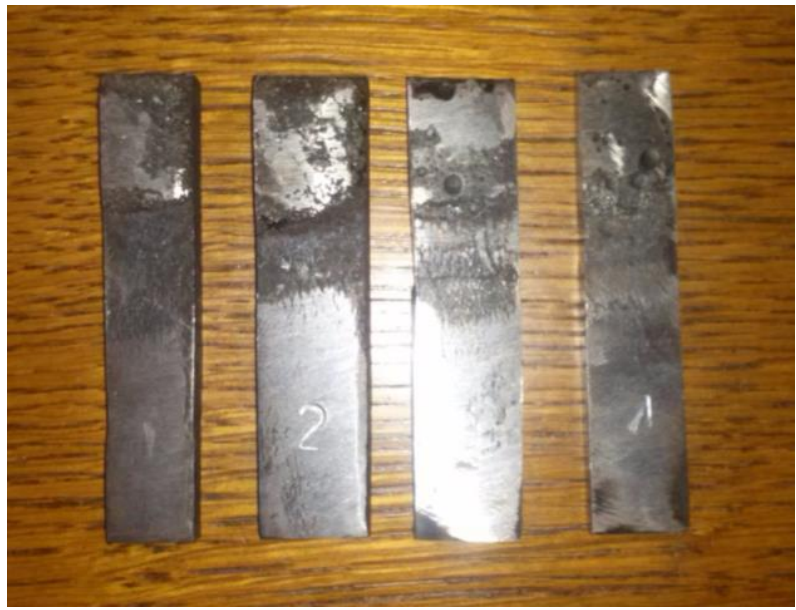

Fig. 4. Samples of the cutters' hardsurfacing overlays, prepared for X-ray phase analysis

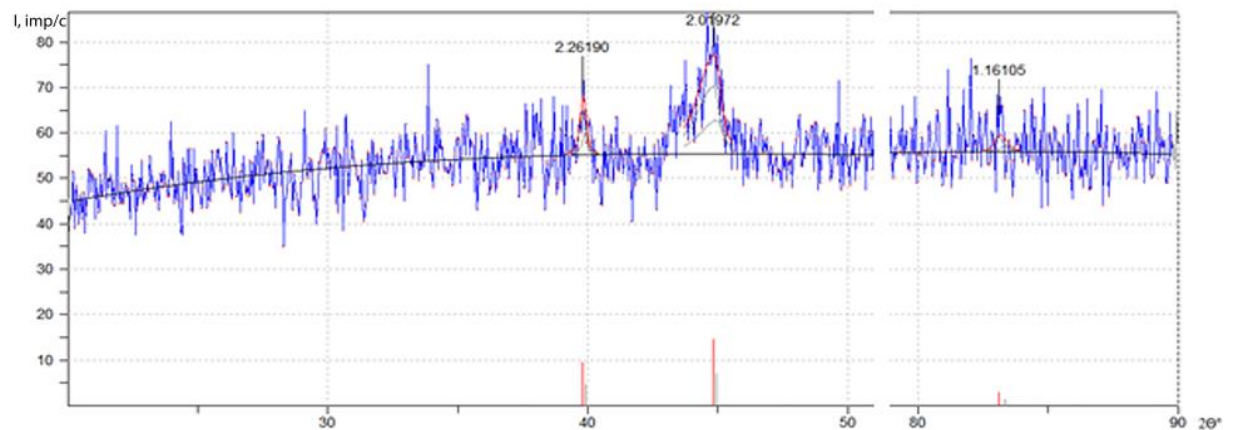

Fig. 5. X-ray of the samples 1 and 2

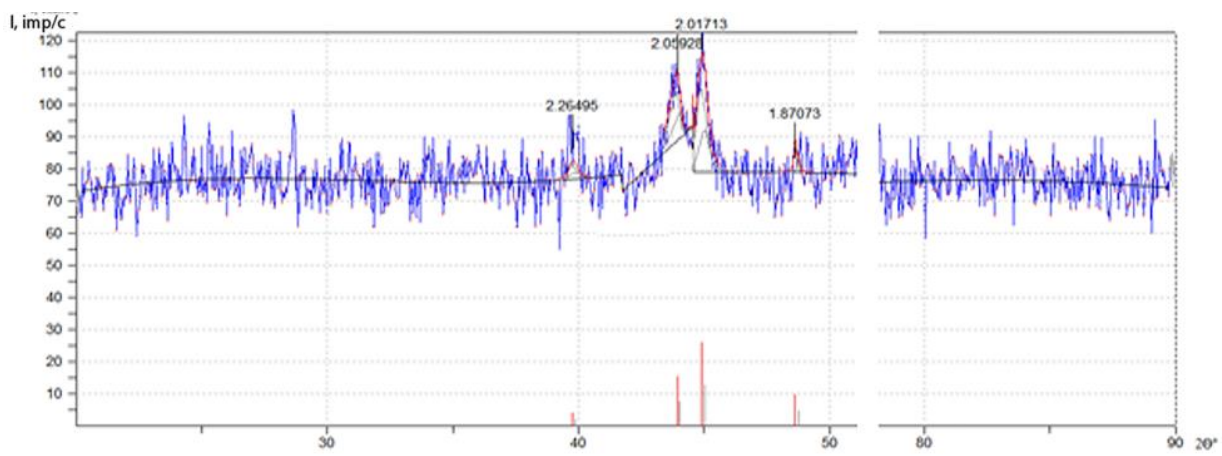

Fig. 6. X-ray of the sample 3 

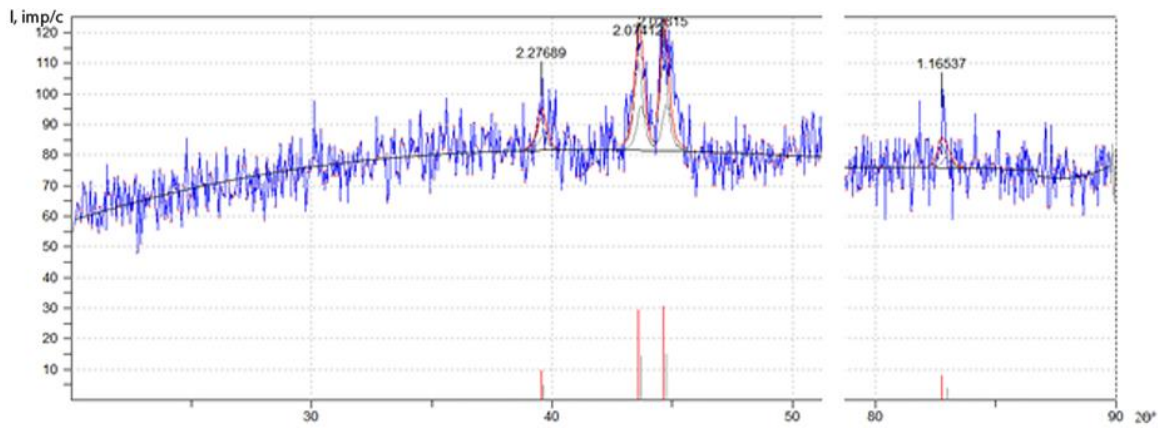

Fig. 7. X-ray of the sample 4

Tab. 4. Results of radiographs decoding by JCPDS card index

\begin{tabular}{|c|c|c|c|c|c|}
\hline \multirow[t]{2}{*}{ Sample } & $2 \theta,{ }^{\circ}$ & $\begin{array}{c}\text { Imax, } \\
\%\end{array}$ & $\mathrm{~d}, \AA$ & $\mathrm{d}, \AA$ & $\begin{array}{c}\text { Entity } \\
\text { with } \mathrm{P}>0,90\end{array}$ \\
\hline & \multicolumn{3}{|c|}{ experiment } & \multicolumn{2}{|c|}{ by card index } \\
\hline \multirow[t]{3}{*}{1,2} & 39.8413 & 12.0 & 2.26215 & $\begin{array}{l}2.27 ; 2.255 ; 2.255 \\
2.258\end{array}$ & $\begin{array}{l}\mathrm{FeC}, \mathrm{Cr}_{7} \mathrm{C}_{3}, \\
\mathrm{Fe}_{7} \mathrm{C}_{3}, \mathrm{WC}\end{array}$ \\
\hline & 44.8369 & 14.7 & 2.01972 & $\begin{array}{l}2.02 ; 2.016 ; 2.017 ; \\
2.019\end{array}$ & $\begin{array}{l}\alpha-\mathrm{Fe}, \mathrm{FeC}, \\
\mathrm{CrC}, \mathrm{Cr}_{7} \mathrm{C}_{3}, \\
\mathrm{Fe}_{7} \mathrm{C}_{3}\end{array}$ \\
\hline & 83.1430 & 10.9 & 1.16080 & 1.159 & $\mathrm{Cr}_{7} \mathrm{C}_{3}$ \\
\hline \multirow[t]{4}{*}{3} & 39.5869 & 14.2 & 2.26495 & $2.26 ; 2.26$ & $\mathrm{Fe}_{3} \mathrm{C}$ \\
\hline & 43.9301 & 15.6 & 2.05928 & $2.06 ; 2.06 ; 2.06$ & $\mathrm{Fe}_{3} \mathrm{C}$ \\
\hline & 44.8975 & 26.1 & 2.01713 & $2.02 ; 2.02 ; 2.02$ & $\mathrm{Fe}_{3} \mathrm{C}$ \\
\hline & 48.6285 & 9.9 & 1.87073 & $1.87 ; 1.87 ; 1.87$ & $\mathrm{Fe}_{3} \mathrm{C}$ \\
\hline \multirow[t]{4}{*}{4} & 39.5457 & 9.9 & 2.27689 & $\begin{array}{l}2.27 ; 2.255 ; 2.255 \\
2.258\end{array}$ & $\begin{array}{l}\mathrm{FeC}, \mathrm{Cr}_{7} \mathrm{C}_{3}, \\
\mathrm{Fe}_{7} \mathrm{C}_{3}\end{array}$ \\
\hline & 43.5997 & 29.5 & 2.07412 & $2.06 ; 2.06 ; 2.06$ & $\mathrm{Fe}_{3} \mathrm{C}$ \\
\hline & 44.0403 & 30.8 & 2.02815 & $2.02 ; 2.02 ; 2.02$ & $\mathrm{Fe}_{3} \mathrm{C}$ \\
\hline & 82.7455 & 8.4 & 1.16537 & 1.159 & $\mathrm{Cr}_{7} \mathrm{C}_{3}$ \\
\hline
\end{tabular}

As follows from the data given in Table. 4, all boron carbide introduced into the samples 1 and 2 was completely absorbed by the overlays, however, the boron concentration and induction surfacing time ( $\sim 1 \mathrm{~min})$ turned out to be insufficient for the new boride phases formation in the overlays; therefore, all boron, obviously, is in the overlays in the form of solutions, is a part of the eutectics, and changes the solubility and dispersion of the carbide phases present in them. In addition, additionally introduced carbon from boron carbide to the material changes the ratio $\mathrm{Me}: \mathrm{C}$ (where $\mathrm{Me}=\mathrm{Cr}, \mathrm{Fe}$ ), which leads to an increase in the wear-resistant carbides $\mathrm{Cr}_{7} \mathrm{C}_{3}, \mathrm{Fe}_{7} \mathrm{C}_{3}$ proportion in overlays and increase their hardness and potential wear resistance. A decrease in the hardness of the sample 2 (see Table 1) can be explained by its macro-defect structure, the presence of pores, cracks and impurities of unreacted boron carbide.

Enhanced growth of dendrites and dilution of the deposited material with base iron in the sample 3 also leads to a change in the ratio Me:C, therefore, one of the main phases is cementite $\mathrm{Fe}_{3} \mathrm{C}$ on its X-ray.

Suppression of dendrite growth by preliminary electrospark ligation base material surface by VK alloy and P6M5 steel for the sample 4, leads to a decrease in the amount of cementite 
in the overlay and the retention of wear-resistant carbides $\mathrm{Cr}_{7} \mathrm{C}_{3}, \mathrm{Fe}_{7} \mathrm{C}_{3}$, which, however, turn out to be pushed back to the interface between the base and the weld metal.

\section{Conclusion}

In the course of the studies carried out, it was found that the use of tungsten and boron carbides as modifiers of the wear resistance of the cutters' hardsurfacing overlay based on hard alloy PG-S27, leads to a change in its chemical composition, structure and properties.

As the optimal content of modifier components (based on the price / quality ratio, hardness and manufacturability), it is possible to use: wt. \%: Wolfram carbide - till 5-8, boron carbide - not higher 1,5. At the same time, to prevent the formation of pores and cracks, the amount of the metal part of the charge should not be less $78-80 \mathrm{wt}$. \%, and the size of boron carbide particles should be set to the minimum - 0,05-01 mm.

Thus, the best option (method) of hardening from the investigated patterns is the 1st (charge Rostov 1), with additional adjustment of the tungsten carbide content to 8-10 wt. \%.

\section{References}

1. V.M. Kishurov, V.N. Ippolitov, M.V. Kishurov, Russian Engineering Research 33(12), 727-730 (2013).

2. Y.J. Zhou, Y. Zhang, Journal of Alloys and Com-pounds 466(1-2), 201-204 (2008)

3. D.A. Ivanov, O.N. Zasukhin, Metal technology 9, 39-43 (2016)

4. S. Guo, N. Chun, Journal of Applied Physics 109(10), 103505 (2011)

5. S. Guo, N. Chun, Progressing Science: Materials International 21(6), 433-446 (2011)

6. W. YehJien, S. Chen, S. Lin, Materials Chemistry and Physics 103(1), 41-46 (2007)

7. S.S. Mahlalela, Journal of the Southern African Institute of Mining and Metallurgy 117(10), 947-953 (2017)

8. L.J. Zhang, J.X. Zhang, Materials Characterization 93, 136-149 (2014)

9. X. Bai, X. Zhang, Materials Research Bulletin 41(2), 387-395 (2006)

10. D.H. Jeong, J.H. Kim, Int. J. Mod. Phys.: Conference Series 6, 367-372 (2012)

11. H. Lee, N. Kim, J. Mater. Process. Technol. 212, 1116-1122 (2012)

12. W. Tao, L. Li, Y. Chen, Int. Journal of Advanced Manufacturing Technology 77, 621-628 (2015)

13. L. Li, W. Tao, G. Peng, Journal of Materials Engineering and Performance 25, 3783-3792 (2016)

14. A. Ishkov, V. Malikov, A. Shegolev, Materials Science Forum 1022, 127-135 (2020) 